\title{
Homeopathic drainage for vaccinated children
}

\author{
Volume 3 Issue 3 - 2016 \\ Michel Bouko Levy \\ Homeopathic Practitioner, Bouko Levy Medical Office, France \\ Correspondence: Michel Bouko Levy, Homeopathic \\ Practitioner, Bouko Levy Medical Office, Marseille 08, Provence- \\ Alpes-Côte d'Azur, France, \\ Emailinfo@homeopathicdrainge.com
}

\section{Perspective}

Among all the vaccinations performed today - the strongest scientific experience about the disease itself and its vaccination results is with DTaP and MMR (Figure 1).

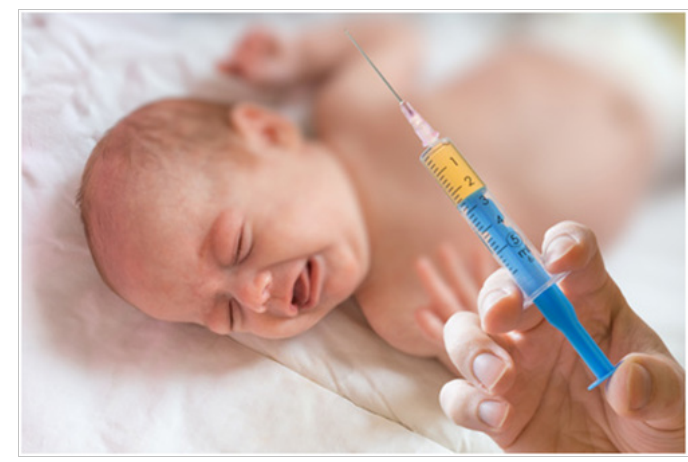

Figure I Homeopathic Drainage for Vaccinated Children.

Two essential vaccinations performed during infancy - D.P.T.P. and M.M.R - present severe side-effects and will induce recurrent pathologies similar to the vaccine toxic agents. The first booster might open a Pandora's Box. Side effects must be analyzed with meticulous care - capricious, weeping, insomnia, fever, skin, thirst, abscess, otitis, etc. - along with the rhythm and periodicity of the different diseases Homeopathic Drainage must be performed in the infant or child who presents diseases and/or changes in behaviour following the booster, from the first minutes after the injection and up to 3 months later.

The ISOTHERAPEUTIC OF VACCINATION must be used after Homeopathic Drainage: one dose in $15 \mathrm{CH}$ and going up to $200 \mathrm{~K}$ then MK and XMK as needed. Note the reaction after the remedy - in most cases they happen around the 8th day. A skin rash augurs well - fever and physical symptoms are to be taken more seriously - neurological reactions such as nightmares testify a deep impact and sensitiveness of the Toxin.

\section{DTaP}

About $50 \%$ of children have reactions in the first days following the booster, such as local inflammation, fever, loss of appetite, otitis, rhinopharyngitis, and cough. Some have severe symptoms such as abscess, asthma, eczema or even neurological disorders - weeping and screaming, restlessness or sleepiness, nightmares, and convulsions. The distant consequences are of the same order with a dominance of respiratory tract pathologies from E.N.T. to lungs - but also intestines, colon, bacterial, fungal, and parasitic disorders. The vaccination aggravates the existing hereditary immune system weaknesses and causes an immune blockage.

\section{MMR}

Measles dominate the MMR pathologies with allergies, conjunctivitis, rhinitis, spasmodic coryza, nose obstruction, cough, hay fever and asthma, physical and psychological growth disorders - essentially decalcification and language - and all the Tuberculin
Received: February 18, 2016 | Published: February 22, 2016 anergic diseases. Boosters might provoke a local abscess, screaming, restlessness, sleepiness, nightmares, fever. All children presenting "measles-like syndromes" during the week following the booster called classical side-effects - need a specific homeopathic treatment.

\section{Homeopathic drainage protocol}

The immune system has a hereditary program which must be studied during the first years of the infant and child through his diseases and the side effects appearing from the boosters, all has to be noted in the Line of Life. The person with an immune dysfunction from a vaccination will present recurrent diseases most likely similar to the toxin effects. The Wheel of Emunctories might be disrupted from its elimination function - apart from the skin - first at all digestive and respiratory levels. In most chronic cases, a prolonged Homeopathic Drainage protocol is required before a Toxin remedy can be given.

Analyze the family pathologies - mother and father, sisters and brothers, aunts and uncles. The treatment contains 3 levels: Homeopathic Drainage of the sensitive organs, Constitutional fortifying, and Reactive Modes regulation with Central and Satellite remedies. Add Tissue salts, it is always very beneficial for children. Oligotherapy is used in mild cases, Organotherapy is helpful when severe recurrent pathologies, Phytogemmotherapy is very effective but it contains alcohol and has to be handled accordingly.

\section{Central remedies}
a. Just after the booster, one dose: ARNICA $15 \mathrm{CH}$
b. The day after, one dose: SILICEA $15 \mathrm{CH}$
c. 2 weeks later, one dose: THUYA $15 \mathrm{CH}$

\section{Before inoculation}

Start one month before: Mineral salts can be used in association or alternated according to each individual evolution. 1 to 3 tablet a day of the corresponding Mineral salt of the infant: 
a. Premature or ill-looking: SILICEA 6DH

b. Stout and healthy looking: CALCAREA CARBONICA 8DH

c. Thin and fragile child: CALCAREA PHOSPHORICA 6DH Immune system

a. One dose every 2 weeks: THYMUSINUM 9CH

b. Morning: COPPER GOLD SILVER TRACE ELEMENT

c. Evening: MANGANESE COPPER TRACE ELEMENT

In case of fragile child, add 5 to 20 drops a day

a. Morning: RIBES NIGRUM BUDS 1DH

b. Evening: ROSA CANINA YOUNG SHOOTS 1D

\section{After inoculation}

Local inflammation with or without fever, abscess-like:

1. Alternate every hour 3 granules as needed of ARNICA 4CH / BELLADONNA 4CH / LEDUM 4CH

2. Local treatment: wet compresses with CALENDULA MT and ECHINACEA MT

Appearance of pathologies similar to the vaccination Toxins

a. Carbonic: one dose a month of CALCAREA CARBONICA $15 \mathrm{CH}$

b. Phosphoric: one dose a week of CALCAREA PHOSPHORICA $15 \mathrm{CH}$

\section{Reactive modes regulation}

\section{Psoric drainage}

Rapid reactions to the booster, alternation of the pathologies from the outside to the inside and reverse - all kind of skin reactions, abscess, itching, anorexia, vomiting, diarrhea, weight loss, food allergies (especially milk) recurrent inflammatory fever - diseases start suddenly and the patient recovers fast.

i. 3 granules a day of ALOE / CALCAREA SULFURICA / CINNABARIS / a.a.p. 4CH

ii. One dose a week in the following order:

iii. 1st week: NUX VOMICA $15 \mathrm{CH}$

iv. 2nd week: HEPAR SULFUR $15 \mathrm{CH}$

v. 3rd week: BELLADONNA $15 \mathrm{CH}$

vi. 4th week: PSORINUM 9CH

Chronic adenitis, repeated sudden fever, weight loss, thinness, dermatitis, parasitism: one dose a week of PSORINUM 9CH then $15 \mathrm{CH}$ then $30 \mathrm{CH}$.

Diarrhea and fever after booster, spasmodic colitis, long lasting bronchitis: one dose a week of PARATHYPHOIDINUM B 9CH then $15 \mathrm{CH}$ then $30 \mathrm{CH}$.

\section{Skin reactions}

a. One dose a month as needed of SULFUR IODATUM 9CH then $15 \mathrm{CH}$ and $30 \mathrm{CH}$

b. For itching eruptions, add 3 granules a day of APIS $4 \mathrm{CH}$ and HISTAMINUM 4CH

\section{Tuberculinic drainage}

Violent reactions and progressive loss of energy, recurrent exhausting fever, respiratory system involved in most inflammation flare ups, lymph nodes recurrent and chronic, allergies:

Lymph nodes drainage

a. 10 drops a day: AGRAPHIS / CISTUS / MERCURIUS / a.a.p. $4 \mathrm{CH}$

b. In severe cases, add LYMPHATIC GANGLION / SURRENINE a.a.p. $4 \mathrm{CH}$

c. 1 or 3 tablets - 1 to 3 times a day - of ALL TWELVE TISSUE SALTS

One dose a week in the following order

a. 1st week: SULFUR IODATUM 9CH

b. 2nd week: PULSATILLA 15CH

c. 3rd week: AVIAIRE 9CH

d. 4 th week: SILICEA $15 \mathrm{CH}$

Loss of appetite and weight: one dose a month of NATRUM MURIATICUM $15 \mathrm{CH}$ followed the day after by one dose of SILICEA $15 \mathrm{CH}$.

Otitis, acute and subacute, Eustachian tube chronic obstruction, recurrent fever with loss of appetite and energy, spasmodic cough: one dose every other week of AVIAIRE $9 \mathrm{CH}$ to $15 \mathrm{CH}$.

Whooping cough like disease, spasmodic cough from nose obstruction, laryngitis, twitches, convulsions, delay of growth and psychomotor development: one dose a month of PERTUSINUM $15 \mathrm{CH}$.

\section{Severe tuberculinic reactions}

Asthma, severe acute attacks during the night, thinness, restlessness and exhaustion: one dose every other week of ARSENICUM ALBUM $15 \mathrm{CH}$. Every cold makes a cough, hoarseness $<$ in the morning and $>$ when lying: alternate one dose every other week of MANGANUM ACETICUM 9CH / STANNUM IODATUM 9CH.

Il-looking with profuse sweating of the head and soles, big skull on skinny body, obstinate: alternate one dose every other week of NATRUM MURIATICUM 15CH / SILICEA 15CH.

Thinness, rapid loss of appetite, profuse sweat, slow and difficult growth, headaches:

a. One dose a week: CALCAREA PHOSPHORICA 15CH

b. One dose as needed: TUBERCULINUM 9CH to XMK

\section{Sycotic drainage}

Recurrent discharge especially in E.N.T. organs, nose obstruction and its reactional symptoms, centripetal reactions by adenoids, polyps, and warts - lack of reaction to heavy allopathic treatments, bacteria and fungus sensitization:
a. 10 drops of CALCAREA CARBONICA 8DH / TEUCRIUM 3DH / THUYA 8DH / a.a.p.
b. One dose a week in the following order:
c. 1st week: THUYA $15 \mathrm{CH}$ 
d. 2nd week: NATRUM SULFURICUM 15CH

e. 3rd week: DULCAMARA 15CH

f. 4th week: SILICEA $15 \mathrm{CH}$

Bronchitis, bronchiolitis, asthma: one dose every other week of NATRUM SULFURICUM 15CH / DULCAMARA 15CH.

\section{Acknowledgments}

None.

\section{Conflicts of interest}

Author declares there are no conflicts of interest.

\section{Funding}

None. 